\section{Changes in the perception of biological $X$-ray absorption spectroscopy between ICBIC 1 and ICBIC 10/BIOXAS 2001: how far have we travelled?}

\author{
M. C. Feiters ${ }^{a_{*}}$ and S. Mangani ${ }^{b}$
}

${ }^{a}$ Department of Organic Chemistry, University of Nijmegen, 1 Toernooiveld, NL-6525 ED Nijmegen, The Netherlands, and ${ }^{b}$ Dipartimento di Chimica, Università di Siena, Via Aldo Moro, 53100 Siena, Italy.E-mail: mcf@sci.kun.nl

The proceedings of BIOXAS 2001 (Siena, Italy, 2001) and both current and planned activities in the field of biological X-ray absorption spectroscopy are discussed against the perspective of changes in the perception of the technique since ICBIC 1 (Florence, Italy, 1983).

\section{Keywords: biological X-ray absorption spectroscopy.}

The last session of BIOXAS 2001 (Third Conference on Biological $X$-ray Absorption Spectroscopy) in Siena, which was organized as a satellite meeting of ICBIC 10 (Tenth International Conference on Bioinorganic Chemistry) $\dagger$ in Florence, was a good point in time to pause for a moment and consider the changes in the perception of biological EXAFS in the time elapsed since the first ICBIC held in Florence in 1983. $\ddagger$ As Brian Hoffman mentioned in his summing up of ICBIC 10,§ EXAFS, Mössbauer and resonance Raman are now accepted techniques that inorganic biochemists use almost routinely. At ICBIC 1, however, these techniques were relatively new and, in particular, EXAFS was looked at with suspicion. A few examples serve to illustrate this.

The conference was opened by Max Perutz $\uparrow$ with a plenary lecture (Perutz, 1983) criticizing EXAFS spectroscopists (Eisenberger et al., 1978) who claimed to have proved his model for the cooperativity of hemoglobin wrong because the iron could not possibly move as far out of the plane of the heme as proposed. Perutz had repeated the EXAFS experiments with Samar Hasnain and Jim Penner-Hahn (Perutz et al., 1982) but found that the displacement of the iron from the heme plane could not be deduced from such data. Although the EXAFS results had essentially been reproduced and led to an agreement, as highlighted in a joint communication of Max Perutz and Bob Shulman (Fermi et al., 1987), that there is a displacement of the iron from the heme plane but not larger than $0.3 \AA$, it was apparently easy at the time to gain a wrong impression about the reliability of EXAFS measurements and simulations (Galloway, 1985).

There was also a special Round Table at ICBIC 1, convened and chaired by Ed Stiefel, called 'Are synchrotron radiation studies (including EXAFS) really breakthroughs in structural studies of metalloproteins?' (Stiefel, 1983), where some of the proponents of

\footnotetext{
$\dagger$ Abstracts of the Tenth International Conference on Bioinorganic Chemistry are compiled in J. Inorg. Biochem. (2001). 86.

$\ddagger$ Abstracts of the First International Conference on Bioinorganic Chemistry are compiled in Inorg. Chim. Acta (1983). 79.

$\S$ Notes on the concluding remarks of ICBIC 10: 'From ICBIC 1 to ICBIC 10: how far have we travelled?' were kindly made available by Professor B. M. Hoffman.

- Deceased, 6 February 2002. An Obituary may be found on page 59 of this issue.
}

the new technique were given a hard time by a critical audience. Finally, at the beginning of the poster session, one of the authors (MCF) was greeted at his poster, which described some preliminary results on EXAFS studies of lipoxygenase and models (Feiters et al., 1983), by R. J. P. Williams with the words 'Now let us discuss why this cannot be true'.

As signalled by Brian Hoffman at ICBIC 10, EXAFS has become an accepted technique that bioinorganic chemists use when they need it. The clearest illustration of how the appreciation of the technique has changed was that one of the poster prizes was awarded to Daresbury Laboratory's Lorry Murphy for her synchrotron radiation study (including EXAFS!) of the $\mathrm{Cu}$ environment in the complex with the prion protein (Murphy et al., 2001; Hasnain et al., 2001) which was also presented, both as a lecture and a poster, at BIOXAS 2001. As the biological X-ray absorption community, we can now truly say that the winter of our discontent has been turned into glorious summer.

In the time between ICBIC 1 and ICBIC 10, an important part of the discussion on EXAFS has centred around what the technique can add to high-resolution crystal structures. Such contributions can be corrections of crystal structures, as in the case of some iron-sulfur proteins (George \& George, 1988), and refinement of metal sites in metalloproteins to subatomic resolution (Hasnain \& Hodgson, 1999). The complementarity of EXAFS and X-ray crystallography results has been recognized and this has now even resulted in joint beamlines being constructed.

As has been pointed out in some recent highlights (George et al., 1998; Meyer-Klaucke \& Strange, 2000), however, X-ray absorption spectroscopy has more to offer than refinement of crystal structures. In the lectures and posters at BIOXAS 2001, we saw a variety of interesting metalloprotein structures, some linked to crystallographic work and some linked to some other spectroscopy, e.g. NMR, or a computer-predicted protein structure. In addition to the metalloprotein work, there were reports from various areas ranging from medicinal chemistry, pharmaceutical chemistry and environmental chemistry, to biomineralization. The molecular scope of the studies ranged from the relatively small synthetic biomimetic supramolecular enzyme models to the largest biological assemblies known, the giant annelid hemoglobins. There were developments on new cells for use with organic solvents, and for proteins under high pressure. On the theoretical front, there were presentations on error analysis by the Monte Carlo approach, and both development and applications of new programmes to allow reliable and rapid simulation of XANES. Some of the presentations had a post-genomic perspective.

In a way, the BIOXAS community can be likened to the city of Siena: the observant visitor notices that it consists of highly competitive contrada's which live in rivalry, and may not all have their own synchrotrons and simulation programmes but certainly have their own drumbands; however, to the average group of tourists or conference delegates it will appear as a unity. In order to maintain the unity of the BIOXAS community, it is important that it continues to meet to discuss problems and to exchange solutions. In recent years, we have seen the start of several successful initiatives, viz. the first BIOXAS (X-ray Absorption Spectroscopy for Biology) workshop organized at the ESRF by Michael Borowski, José Goulon, Peter Lindley, Sakura Pascarelli and Armando Solé in February 1999, the 'Advanced Training Course in the Use of Fluorescence X-ray Absorption Spectroscopy in Biology', organized at the EMBL Hamburg Outstation by Wolfram Meyer-Klaucke and Paola d'Angelo in June 1999, and the BioXAS Study Weekend 'Contribution of BIOXAS to Structural Genomics: Developments in Theory and Refinement Methods', organized at LURE (Orsay) by Isabella 
Ascone, Roger Fourme and Samar Hasnain in June/July 2001. $\dagger$ The BIOXAS initiative has already been continued as BIOXAS 2000 in Orsay in July 2000, and as BIOXAS 2001 last September in Siena. The BIOXAS conferences and study weekends will be organized alternately in the coming years, and there are also plans for another advanced course. Collaborative actions, in Europe and/or worldwide if possible, will be taken to ascertain the continuity of such initiatives, and to work towards a unification of the best elements of the existing theories for application in biological X-ray absorption spectroscopic problems.

The BIOXAS 2001 meeting was concluded with two rounds of applause, one for all the speakers and the participants who had prepared posters and taken part in the discussions, and one to thank Stefano Mangani and Manuela Benvenuti and other organizers from the University of Siena for hosting and organizing an excellent meeting.

$\dagger$ The proceedings of the BioXAS Study Weekend will be compiled in the July (2002) issue of the Journal of Synchrotron Radiation.

\section{References}

Eisenberger, P., Shulman, R. G., Kincaid, B. M., Brown, G. S. \& Ogawa, S. (1978). Nature (London), 274, 30-34.

Feiters, M. C., Vliegenthart, J. F. G., Reedijk, J. \& Malmström, B. G. (1983). Inorg. Chim. Acta, 79, 148.

Fermi, G., Perutz, M. F. \& Shulman, R. G. (1987). Proc. Natl. Acad. Sci. USA, 84, 6167-6168.

Galloway, J. (1985). Nature (London), 318, 602.

George, G. J. \& George, S. J. (1988). Trends Biochem. Sci. 13, 369-370.

George, G. J., Hedman, B. \& Hodgson, K. O. (1998). Nature Struct. Biol. 5, 645-647.

Hasnain, S. S. \& Hodgson, K. O. (1999). J. Synchrotron Rad. 6, 852-864.

Hasnain, S. S., Murphy, L. M., Strange, R. W., Grossman, J. G., Clarke, A. R., Jackson, G. S. \& Collinge, J. (2001). J. Mol. Biol. 311, 467-473.

Meyer-Klaucke, W. \& Strange, R. W. (2000). Synchrotron Rad. News, 13, 17 21

Murphy, L. M., Hasnain, S. S., Strange, R. W., Grossman, J. G., Clarke, A. R., Jackson, G. S. \& Collinge, J. (2001). J. Inorg. Biochem. 86, 351.

Perutz, M. F. (1983). Inorg. Chim. Acta, 79, 2-3.

Perutz, M. F., Hasnain, S. S., Duke, P. J., Sessler, J. L. \& Hahn, J. E. (1982). Nature (London), 295, 535-538.

Stiefel, E. I. (1983). Inorg. Chim. Acta, 79, 86 